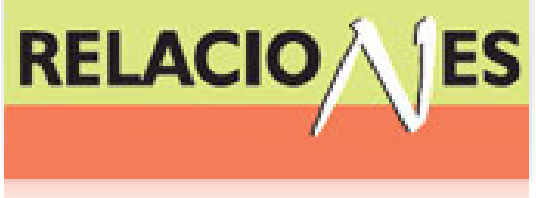

Relaciones. Estudios de historia y sociedad ISSN: 0185-3929

relacion@colmich.edu.mx

El Colegio de Michoacán, A.C

México

Zárate H., J. Eduardo

Comunidad, reformas liberales y emergencia del indígena moderno. Pueblos de la Meseta Purépecha

(1869-1904)

Relaciones. Estudios de historia y sociedad, vol. XXXII, núm. 125, 2011, pp. 17-52

El Colegio de Michoacán, A.C

Zamora, México

Disponible en: http://www.redalyc.org/articulo.oa?id=13718526002

Cómo citar el artículo

- Número completo

- Más información del artículo

Página de la revista en redalyc.org

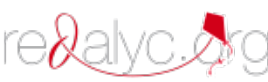

Sistema de Información Científica

Red de Revistas Científicas de América Latina, el Caribe, España y Portugal Proyecto académico sin fines de lucro, desarrollado bajo la iniciativa de acceso abierto 


\title{
Comunidad, reformas liberales y emergencia del indígena moderno. Pueblos de la Meseta Purépecha (1869-1904)
}

\author{
J. Eduardo Zárate H.* \\ EL COLEGIO DE MICHOACÁN
}

El presente artículo analiza el impacto que tuvieron las reformas liberales del siglo xix en las comunidades indígenas de la Meseta Purépecha en Michoacán, no sólo en la reconfiguración de su territorio sino en la emergencia de un indígena moderno. Con base en la documentación que generaron las propias comunidades se revisan los argumentos que esgrimieron para presentarse como sujetos con derechos individuales a la vez que colectivos y negociar con el Estado mexicano la privatización de sus tierras comunales.

(Comunidad indígena, Estado mexicano, nación, ciudadanía compleja, reformas liberales, territorio)

\section{INTRODUCCIÓN}

pesar de que el reparto agrario de siglo xix y principios del
xx estuvo plagado de irregularidades, es indudable que las
leyes liberales impactaron las maneras de concebirse y presentarse de las comunidades indígenas. Las comunidades de indios no sólo resistieron e intentaron, con todos los medios a su alcance, manipular, ocultar o simular la aplicación de las leyes liberales, también adoptaron elementos del nuevo discurso cívico y ciertas formas de representación acordes con las nuevas exigencias de las leyes nacionales. El objetivo que se perseguía era claro, negociar con el Estado mexicano hasta donde fuera posible el mantenimiento de sus bienes, formas de vida y representación política, es decir, una cierta

\footnotetext{
*zarate@colmich.edu.mx
} 
autonomía que les permitiera mantener el control comunal de sus recursos. Visto a la distancia, este proceso que se inicia en el siglo XIX hizo posible la emergencia de un sujeto indígena que a partir de entonces reivindicará la colectividad como posibilidad de vida en el mundo moderno.

De alguna manera, el que en la actualidad en muchas regiones se observe un vigoroso comunalismo, incluso en localidades que durante gran parte del siglo $\mathrm{xx}$ se identificaran simplemente como campesinas ahora lo hagan también como indígenas, nos demuestra el alcance que tuvieron las estrategias indígenas por mantener el control de sus territorios además de la notable continuidad de los reclamos de reconocimiento como sujetos colectivos por parte del Estado nacional.

Por ejemplo, el proceso histórico de la comunidad de Sevina, ubicada en la meseta purépecha en el municipio de Nahuatzen, refleja de manera clara esta vigencia. En los documentos del siglo XIX se dice que Sevina fue una de las primeras comunidades de la región en repartirse, en 1874 manifestaba, como muchas otras comunidades, que no tenía tierras comunales. ${ }^{1} \mathrm{Y}$ sin embargo, durante una

${ }^{1}$ El 25 de marzo de 1874, el Prefecto de Uruapan da cuenta de que se ha realizado el reparto en las excomunidades de Jucutacato y Sevina: "Tengo el honor de remitir a Usted para conocimiento del C. Gobernador ocursos que le dirigen las comisiones repartidoras de los terrenos de las extinguidas comunidades de indígenas de los pueblos de Jucutacato y de Sevina de este Distrito, pidiendo se apruebe por ese supremo gobierno, el reparto que han hecho, sin sujetarse a las prescripciones de la Ley de 13 de Diciembre de 1851 pero siguiendo los principios de justicia y equidad en que ella está basada”.

Dichos ocursos que van debidamente informados por esta prefectura acompañan el de la comisión de Jucutacato, un expediente con ocho fojas útiles y el padrón respectivo que consta de treinta y siete, y el de Sevina un expediente compuesto de ocho fojas útiles y el padrón de ciento veinte".

La Secretaría de gobierno le responde que el gobierno del estado aprobó dicho reparto:

Prefecto de Uruapan.

"El C. Gobernador ha tenido a bien aprobar el reparto de los terrenos pertenecientes a las comunidades de indígenas de Jucutacato y Sevina los procedimientos no están arreglados en un todo a la ley del 13 de diciembre de 1851, sin embargo se han seguido en esencia los principios de justicia y además consta la conformidad de la mayoría de los interesados, cuyos requisitos bastan para que este gobierno apruebe dichos repartos [...] y para que esa prefectura lo haga saber a quienes correspondan, en la inteligencia de que quedan a salvo los derechos de los dueńos de algunos terrenos que sin pertenecer a las comunidades de que se trata se hallen comprendidas en el reparto, cuyos derechos po- 
buena parte del siglo xx, la comunidad se movilizó y procuró, primero, la recuperación o restitución de sus tierras comunales y, luego, el deslinde definitivo de las parcelas en manos de propietarios particulares y los terrenos que mantenían en disputa con las comunidades vecinas. A principios del siglo xxI, presentará un Estatuto Comunal con toda una reglamentación y una definición de lo que es ser comunero. Además, sus autoridades se mostrarán orgullosas de haber obtenido la carpeta básica definitiva, que otorga la Secretaría de la Reforma Agraria, así como de haber recuperado casi todas las tierras que estaban en manos de particulares y de estar desarrollando varios proyectos colectivos sustentados en la propiedad comunal de su bosque. ¿Acaso era posible que una excomunidad que se había privatizado (además de que se castellanizó desde mediados del siglo xx) pudiera recomunalizarse casi totalmente?, ¿o es que acaso no había existido tal privatización o no como la conocemos y que el proceso había sido mucho más complejo de lo que pensamos?, ¿qué sucedió a finales del siglo XIX y en las décadas posteriores que trastocó este proceso?

Algunas de las respuestas aparecen en el trabajo de Roseberry (2004) quien señala que las reacciones de las comunidades michoacanas al reparto agrario fueron muy diversas y encontradas - hubo desde resistencia abierta, hasta clara aceptación, pasando por la simulación-, además, y es muy enfático en señalarlo, las diferencias y los conflictos internos fueron muy importantes para aceptar, rechazar o negociar con los agentes del Estado las condiciones de la privatización. De acuerdo con Mallon (1995), Roseberry seńala que es posible hablar de un "liberalismo popular" (es decir la adopción y uso del credo liberal por las clases campesinas) pero aclara que éste tuvo muchos matices y no se adoptó de manera generalizada en la zona purépecha. Tanto Gledhill (2004a) como Annino (2003) cuestionan la utilización de dicho concepto. El primero señala que dado los alcances tan limitados que finalmente tuvieron las reformas liberales no se explica el entusiasmo con que algunos autores (de

drán hacer valer entre la autoridad a que crean conveniente [...]” (AGHPEM, hijuelas, libro 3, fojas 35 y 37 ). 
nuevo Mallon y Roseberry) utilizan el término. Por su parte, Annino indica que en todo caso si se habla de un liberalismo popular éste se manifestó mucho más temprano que durante las reformas de la segunda mitad del siglo xIx y se remite al liberalismo borbónico, que por cierto contemplaba la existencia de una república que reconocía corporaciones a la vez que libertades individuales. ${ }^{2} \mathrm{El}$ hecho es que a partir de las reformas liberales del siglo XIX, el discurso con el que se presentan los indígenas se modifica y a la par de que siguen reivindicando el reconocimiento como comunidades se presentan también como ciudadanos que forman parte de la nación mexicana e incluso en algunos lugares adoptan fervientemente el credo liberal. Purnell (2004) ofrece otra perspectiva importante, presenta los casos de comunidades que siguieron caminos divergentes. Uno, San Juan Parangaricutiro, donde la comunidad a través de sus autoridades tradicionales resiste y negocia, para finalmente mantener el control de su propiedad comunal prácticamente hasta la actualidad. El otro, Zacapu, en que el gobierno local debilitado por las fuertes divisiones internas terminó por aceptar el reparto y la privatización y luego de la etapa armada de la revolución por solicitar la dotación y conformarse como ejido. Lo que demuestra que no siempre las comunidades que adoptaron la nueva ideología del Estado mantuvieron sus tierras comunales.

De acuerdo con los documentos de hijuelas revisados, principalmente del distrito de Uruapan, la mayoría de las comunidades de la meseta purépecha, tenían algo de los dos tipos que señala Purnell, pero no correspondían ni a uno ni a otro. Lo más importante, pese a manifestar que se habían repartido, es que se mantuvieron como comunidades en su organización interna. De ahí que consideremos que para entender la lógica subyacente a su particular comunalismo,

\footnotetext{
${ }^{2}$ Sumado a esta idea dice Lempérière que "los liberales peninsulares dieron a la sociedad novohispana, con la Constitución de Cádiz, la oportunidad no de constituirse en nación de ciudadanos sino de perfeccionar sus estructuras corporativas y representativas tradicionales" (Lempérière 2003, 322). La primera constitución del México independiente del 4 de octubre de 1824 reconocía por primera y última vez en la historia del mundo hispánico una república corporativa perfecta "aquella tradición republicana no designaba al régimen político, sino el cuerpo político, la comunidad independiente de su forma de gobierno" (Lempérière ibid., 321).
} 
hay que ver el proceso histórico y las distintas representaciones de comunidad que aparecen en los documentos de esta época. Estas comunidades a pesar de las múltiples y diversas presiones a que estuvieron sometidas, sobre todo durante la segunda mitad del siglo XIX y principios del xx, lograron resistir y negociar con el Estado mexicano cierta autonomía y el reconocimiento de sus instituciones, lo que hasta la fecha les ha permitido mantener el control sobre su territorio.

Desde esta perspectiva, las respuestas y los argumentos que las comunidades formularon a las reformas liberales, resultan fundamentales para entender tanto su propia lógica como los procesos y conflictos políticos que aparecerán a lo largo del siglo xx. Pero sobre todo, nos muestran algunos elementos en la conformación de este sujeto histórico que es el moderno indígena mexicano. Utilizamos el término "indígena moderno" en cuanto que desde este momento se asume como actor poseedor de diversas identidades no necesariamente enfrentadas. Lo que constituye un antecedente fundamental para comprender los procesos de reivindicación étnica y comunal que aparecerán a fines del siglo xx. Las respuestas del Estado mexicano a los reclamos de reconocimiento generalmente serán negativas, no hubo ningún intento serio por reconocerles personalidad jurídica en cuanto indígenas, aunque la restitución de las tierras comunales y su reconocimiento como comunidades agrarias durante la primera mitad del siglo xx significó para muchas comunidades la posibilidad de atrincherarse en el ámbito agrario y campesino y desde ahí promover la defensa de su cultura y sus estructuras de representación política.

\section{REFORMAS LIBERALES Y RESPUESTAS LOCALES}

Como es bien sabido, la aplicación de las leyes liberales en el nivel local centraban su ataque en dos aspectos básicos: a) los bienes de las corporaciones o los bienes en común que definían una manera de no ser considerado ciudadano y parte de la nación (su defensa equivalía mantenerse al margen de la nación, en tanto las comunidades conservaban la soberanía sobre su territorio); y, b) el fuerte control ideológico que tenía el clero sobre los espacios públicos de ciudades, 
villas y pueblos. ${ }^{3}$ La transformación de ambos aspectos fue vista por los pensadores liberales de la época como una necesidad apremiante para romper con las estructuras coloniales de manera definitiva y tener verdaderos ciudadanos individuales que se pudieran identificar y sentir parte de la nación mexicana y, que por consiguiente, fueran capaces de reconocer una soberanía única: la del Estado nacional, por encima de sus lealtades e identidades locales.

Uno de los resultados fue la conformación de una nueva cultura política resultado de la mezcla (o hibridación) entre los valores colectivos y los propios del liberalismo. Lira $(2003,389)$ afirma que "la desamortización marca el inicio de otro momento en la historia de México, pero no llega a disolver las comunidades ni logra integrar a los indígenas a la sociedad individualista”. Aun cuando desde principios del siglo XIX, con los ordenamientos de distribución de tierras de 1824-1828, "el proceso de apropiación individual de la tierra se había extendido por todo el país alterando el orden tradicional en las regiones de antiguos pueblos de indígenas" (Lira, p. $388)$. Con lo que coincide Annino $(2003,415)$ quien señala que

Las comunidades mexicanas aceptaron formar parte de la nueva nación, pero al reinterpretar las cartas constitucionales para defender sus intereses acabaron imaginando muchas veces otras naciones mexicanas cuya identidad procedía de versiones actualizadas del pasado. En términos generales, estas versiones utilizaron un procedimiento de yuxtaposición de valores al igual que en la época virreinal. Este sincretismo nuevo entre pueblos y liberalismo no está muy estudiado, [...] Parece, sin embargo, que el fenómeno se dio en forma cíclica según los escenarios creados por las coyunturas agrarias y políticas nacionales.

Como bien sabemos luego de consumada la independencia y hasta principios del siglo xx se orquestó el mayor ataque institucional hacia las comunidades indígenas como forma de organización,

${ }^{3}$ Villegas (1981, 41-42), señala que el objetivo inicial de la Ley Lerdo eran las grandes corporaciones religiosas, sin embargo, al calor de las disputas entre liberales y conservadores se radicalizó su formulación y aplicación incluyendo al final a todo tipo de corporación y abarcando a los pueblos de indios. 
propiedad e identidad, de tal manera que legal y formalmente desaparecieron (se les llamó "ex comunidades", "pueblos" y en el siglo xx "comunidades agrarias"), no así como valor e ideal de vida y en cierta medida como una forma de organización social. Aspectos sobre los cuales las mismas comunidades han argumentado en su defensa en distintos momentos históricos. ${ }^{4}$

Sobre el reparto de tierras del siglo XIX dice Roseberry (2004, 43-44):

Estas leyes fueron diseñadas para abolir las formas corporativas de la tenencia de la tierra [...] y las jerarquías estamentales que fueron creadas en el periodo colonial. También pretendieron la creación de una nación de ciudadanos formalmente iguales. Las reformas estuvieron entrelazadas, pues la eliminación de la tierra comunal en los pueblos indígenas estuvo íntimamente relacionada con la desaparición de la identidad indígena (como un estatus dentro de una jerarquía estamental) y con la formación de ciudadanos.

En tanto proyecto del Estado, entonces, las reformas liberales pretendían abolir la forma de comunidad étnica (entre otras) e introducir una comunidad del Estado compuesta de ciudadanos (individuales) y basada en formas de tenencia de la tierra privadas. Idealmente la jerarquía estamental cedería ante una jerarquía de clases y las comunidades étnicas ante la formación de una comunidad nacional.

Otro de los resultados menos tratado y conocido, fue la redefinición de este nuevo sujeto histórico, consciente de su papel y que ahora tenía la posibilidad de presentarse como ciudadano miembro de una nación y a la vez parte de una colectividad local. Las reformas liberales y su intento de aplicación realmente constituyeron un parteaguas en las comunidades indígenas de Michoacán y sobre todo en la forma de concebirse como sujetos (ya no súbditos de la corona española). Esto puede observarse claramente en las argumentacio-

${ }^{4}$ Aparecerá un problema secundario pero fundamental para las ciencias sociales y posteriormente para el estado plural, cómo identificar y definir a un sujeto indígena en términos jurídicos, ¿como el miembro de una comunidad local?, ¿ como aquel que habla una lengua indígena?, ¿como aquella persona que se siente indígena y pertenece a una comunidad?, ¿como el copropietario de los bienes comunales? 
nes que hacen los representantes de las comunidades y en ocasiones sus apoderados con respecto a las razones para repartirse o no las tierras comunales o, lo que ocurrió frecuentemente, realizar y declarar un reparto a su manera y según sus propios ideales. Lo que a los ojos de los agentes del Estado era una clara simulación. En particular nos interesa destacar tres principios argumentativos a través de los cuales se presentan como sujetos modernos integrados a la nación y en los que reconocen al Estado mexicano como una soberanía. El primero lo podríamos denominar la "ciudadanía compleja", se argumenta y subraya la necesidad de que la nación los reconozca realmente como ellos se conciben a sí mismos y no según el ideal de ciudadano que se pretende imponer. Es decir, esperan que se les considere como ciudadanos de la nación pero con ciertas particularidades que tienen que ver fundamentalmente con su deseo de mantenerse como parte de una comunidad. Esta particularidad se concibe como ineludible para la reproducción social de los individuos y como la contraparte necesaria para reclamarse como sujetos con derechos universales, los cuales no niegan sino también los consideran fundamentales para su reproducción social. El segundo es la consolidación de la idea de comunidad local con una base territorial, a partir del establecimiento de los límites precisos de la propiedad de los pueblos (requisito indispensable de las leyes liberales para realizar el reparto). Aspecto que aunque anteriormente no carecía de importancia, se vuelve esencial en cuanto los recursos que se encuentran en los límites entre comunidades se convierten en estratégicos para el desarrollo y la reproducción local. El tercero es la preocupación por los bosques como valor universal y requisito indispensable para su sobrevivencia material y social, en tanto ahí se concentra la fuente de su riqueza, ahora necesaria o indispensable para insertarse al mercado capitalista y que por lo mismo no puede ni debe estar subordinado al valor económico (aunque insertar los recursos de las corporaciones al mercado capitalista era una de las

${ }^{5}$ Concepto que se deriva de la idea de igualdad compleja propuesto por Walzer (2001), para referirse a la posibilidad que tienen los individuos modernos de pertenecer a varias clases de colectividades sin entrar en contradicción. 
principales apuestas y preocupaciones de las reformas liberales). Pero además, independientemente del uso que se haga de los bosques se antepondrá este valor como uno que debe ser compartido por toda la sociedad y que no es propio de las comunidades indígenas. En el discurso local este principio se articula lógicamente con la ciudadanía compleja y el señalamiento de límites. No es casual que estos tres elementos argumentativos aparezcan en distintos momentos, el primero el de las definiciones a finales de la década de 1860 , el segundo, el de los límites a lo largo de las tres últimas décadas del siglo XIX, y el que pudiéramos denominar "conservacionista" a principios del siglo xx, cuando las compañías madereras -expresión del capitalismo salvaje- hacen su aparición en el área.

\section{La ciudadanía compleja y su defensa}

La definición de un sujeto moderno (o de la ciudadanía compleja) en este caso, se relaciona directamente tanto con la idea de igualdad como de seguridad social. Sin el reconocimiento de las cuales para los indígenas no podría existir la ciudadanía individual y el reconocimiento de la pertenencia a la nación mexicana. En el siguiente documento de la comunidad (o excomunidad) de Tanaco, aparece clara la idea de que al interior de la comunidad se reconoce la propiedad privada, que no todo era de todos y que las propiedades (terrenos, parcelas, solares y casas) eran usufructuados por individuos y familias concretas a quienes pertenecían. Semejante a la respuesta de muchas comunidades que no tenían nada que repartir pues "desde tiempo inmemorial" las tierras estaban repartidas. De tal manera, como dice el documento, pensar en que todo es de todos sería una forma de "apropiarse" lo de otros, simplemente por considerarlo comunal, lo que les produce "repugnancia". En este testimonio (una acta de asamblea de la comunidad de Tanaco) aparece quizá por primera vez el término "indígenas comuneros ciudadanos", como la definición más acabada de la pertenencia y de autorrepresentación frente a las autoridades nacionales. De acuerdo con esta autoadscripción presentan lo que ellos consideran el reparto ideal o el que resultaría menos perjudicial y los problemas que se pueden suscitar 
de no llevarse a cabo de esa manera y querer imponer un ideal que no se ajusta a la realidad. Además se reconoce que en efecto, existen diferencias al interior de la comunidad debido a que algunos miembros han vendido o han acumulado propiedades por herencia. Es decir, aceptan la igualdad de oportunidades tal como lo establece el liberalismo clásico, pero no la consideran como contrapuesta a la vida comunitaria. En sus propias palabras ya habían realizado el "reparto", de las tierras laborables y solares para vivienda, las otras tierras (bosques y montes) pretendían seguir manteniéndolas en común, por lo tanto la ley no les corresponde a ellos.

En el pueblo de Tanaco de la municipalidad de Paracho, reunidos los indígenas comuneros ciudadanos [aproximadamente 100 nombres escritos], y que pudieron reunirse [...] y explicación verbal en los idiomas tarasco y castellano $[\ldots]$ consultando lo que más les conviene y han acordado darse por repartidos en el estado en que están pues no hay terrenos y que puedan propiamente llamarse de comunidad porque todos los que están en posesión de este pueblo están fraccionados y bajo el dominio privado de los comuneros $\mathrm{y} / \mathrm{o}$ familiar $\mathrm{y}$ si no hay igualdad es porque unos han vendido y otros comprado, o porque por herencia les han cabido mayores extensiones: que están conformes en el estado en que están: que como los montes no pueden repartirse quieren gozar en común los pastos y los astilleros; que tienen litigios pendientes con las comunidades de Agüirán, Urapicho y Cheranástico y si obtienen algún [acuerdo] repartirse inmediatamente. [...] así como lo fueron los demás que concurrieron a formarla agregando que esperan que el gobierno no verá como una oposición al reparto este acto, sino como un acto que consideran les conviene porque estando cada uno de los que forman comunidad en posesión de un pedazo que ha habido por herencia de un padre o abuelos sienten repugnancia en tomarle lo de otros, o en que deje de poner el que ha tenido en su poder por los medios dichos. Que por lo expuesto entienden que no los comprende la ley de reparto pues de hecho están repartidos y conforme en cuya virtud firman la presente acta los que saben hacerlo $[\ldots] .^{6}$

${ }^{6}$ Firma: Norberto Mora, Guadalupe Romero y muchas firmas más de comuneros, febrero de 1869 (AHGPEM, hijuelas, libro 12, foja 21). 
Las interpretaciones que se hacían de las circulares que obligaban al reparto de tierras eran muy distintas. La de los funcionarios del Estado era tajante: debían de convertirse en propietarios particulares formales con escrituras de cada lote, la de los comuneros más compleja: aceptaban la propiedad privada pero dentro de la lógica comunal.

La argumentación en contra de la manera en que se estaba llevando a cabo el reparto agrario y de las consecuencias negativas que podría tener, así como la concepción local de la ciudadanía, aparece con toda claridad en el siguiente documento firmado por los comisionados indígenas de los pueblos de Paracho, Aranza y Tanaco. En este documento se enfatiza la necesidad de mantenerse en comunidad como una forma de seguridad y se dan contra ejemplos de comunidades que ya se repartieron y cuyos habitantes ahora están en la pobreza y por el contrario se argumenta que quienes no han aceptado el reparto se encuentran en mejores condiciones de vida. También alegan que las comunidades indígenas no pueden equipararse a las corporaciones eclesiásticas como lo hicieron los liberales radicales y, por el contrario, la comunidad (lo que también aparece en otros documentos) puede equipararse con una sociedad o asociación, al igual que una empresa o compañía moderna con una base contractual. Hay que destacar que la comunidad se considera parte de la sociedad, una parte fundamental (como un modelo de vida) por lo que dañarla perjudicaría o terminaría perjudicando a todo el cuerpo social. Su alegato es por el reconocimiento como ciudadanos colectivos o ciudadanos con características propias, una manera muy particular de buscar la igualdad y la libertad, que nunca estuvo considerada en las propuestas ni de los políticos del siglo XIX y XX, ni de los intelectuales liberales nacionalistas. Es decir, un discurso totalmente opuesto en términos de proyecto social al del Estado mexicano que pretendía mediante la ampliación del mercado abatir las desigualdades. Además sorprende la actualidad del lenguaje utilizado, parecería que son intelectuales formados en nuestra época quienes formulan tal argumentación. Lo que también demuestra la continuidad de la concepción ciudadana local y la persistencia de este sujeto.

En marzo de 1869, las comunidades de Paracho, Aranza y Tanaco "Piden se suspendan los efectos de le ley del 9 de diciembre 
del año pasado y se inicie su derogación ante la Legislatura del Estado". En este documento se destacan las bondades de las leyes coloniales a la vez que reconocen los problemas que ocasionaron. Por una parte, protegieron al indígena, según se afirma, aunque también introdujeron elementos de discordia entre las comunidades. Hay que tener en cuenta que lo nacional o la nación todavía era un proyecto incierto que no ofrecía la misma seguridad a las comunidades, como si lo habían hecho las leyes coloniales. No se trata simplemente de una vuelta al pasado, pero si de cierta precaución para involucrarse en el nuevo proyecto de nación, porque efectivamente también reconocen las posibilidades que les ofrecen los derechos universales ("hombres iguales a los demás").

\section{Gobernador:}

"Florentino Martínez, Prudencio Ramírez, José Dolores Cano y Ángel Lucas, vecinos de Paracho; Vicente Mora y Miguel Gutiérrez, vecinos de Aranza y Pedro Velásquez, Trinidad López, Jerónimo Marcos y Mateo Álvarez, vecinos de Tanaco: exponemos respetuosamente que hemos venido comisionados por los indígenas de nuestros respectivos pueblos a explicar a usted se sirva suspender los efectos de la ley del 9 de diciembre del año próximo pasado e iniciar su derogación ante la Legislatura del Estado, por las razones que breve y sencillamente pasamos a exponer.

Las antiguas leyes coloniales dieron a cada uno de nuestros pueblos el carácter de una corporación o comunidad independiente de sus vecinos aunque estos estuviesen ligados con aquellos por las mismas creencias, por iguales tradiciones, por idénticas costumbres y hasta por la propia lengua; y aunque aparentemente nos concedieron grandes privilegios, lo cierto es que establecieron entre las diversas comunidades elementos de discordia y rivalidad que subsisten aún para desgracia de los no indígenas; pero que entonces permitieron a los conquistadores enraizarse en estas tierras.

El espíritu que ha dominado en las leyes, desde la independencia hasta nuestros días y que se nota más particularmente en la Constitución de 1857 ha hecho de los indígenas de raza pura hombres iguales a los demás, dejando insubsistente el sistema de las comunidades, y como su consecuencia lógica es la supresión de nuestros antiguos privilegios. 
Pero las costumbres inveteradas de las que por fuerza nacen imprescindibles necesidades lejos de poderse cortar de un solo golpe demandan en su extinción una política suave y conciliadora, y una voluntad ilustrada, por parte de aquellos individuos entre los que existe como un hecho esa costumbre, o si se quiere llamarla así, esa preocupación.

Por eso nosotros los indígenas, organizados bajo el imperio de leyes especiales y habituados a sus efectos por más de trescientos años, no pudimos entrar de lleno en la violenta transición que nos indicó la nueva legislación, sino adaptando prudentes reservas que han salvado a la mayor parte de los pueblos, o sufriendo horribles trastornos que han ocasionado la ruina completa de algunas poblaciones que incauta e imprudentemente cambiaron sus costumbres y procedieron al repartimiento de sus terrenos. Hoy sus engańados habitantes miran en poder de extrańas manos el suelo que les aseguraba su subsistencia y acaso convertidos en siervos de los ricos, levantan para estos las pingües cosechas que de otro modo habrían servido para dar vida a sus ahora hambrientas y desoladas familias. Y se agrava este triste cuadro recordando que las ventas de esos terrenos son el resultado de una indolente usura. Los que como nosotros, no hemos querido aceptar el reparto, nos hallamos en mejores condiciones, no estamos a merced de nadie y jamás se da el caso de que uno de nuestros individuos se vea mendingando por las calles o pidiendo asilo en los hospitales del Gobierno.

Y no es que hayamos conservado entre nosotros el sistema antiguo de la comunidad, sino que bajo este nombre hemos establecido por mutuo acuerdo un contrato de vecindad en donde el pobre que no tiene fondos para cultivar sus terrenos, no va a empeñarlos en la casa del rico usurero, sino que acude a sus socios que lo auxilian y no lo dejan arruinarse. Nadie está obligado a vivir forzosamente en esa compañía y si mañana alguno de sus miembros quisiese separarse, saldría de la sociedad llevándose su parte con pleno consentimiento de los demás. Si esto no se verifica todos los días es porque por instinto conoce el indígena que tal conducta le será perjudicial.

Se trata de relativizar la comunidad y de hacer explícita otra manera de entenderla, como una sociedad fundada con base en el interés común de los sujetos a ella adscritos. Aquí también hay una crítica a los postulados liberales de Mora, Otero, Juárez y otros. 
Y no se diga que la comunidad, así constituida, puede equipararse a las corporaciones eclesiásticas y sus bienes a los de la Mano muerta; porque en aquella sus individuos no tienen una acción propia, no pueden separarse si no es renunciando a favor de la sociedad los bienes a que antes tenían derecho, mientras que nosotros todo esto podemos hacer por el carácter de nuestra propia institución y bajo el amparo de las leyes. Y en cuanto a nuestros bienes, ello se transmiten conforme a las leyes comunes, bien sea por testamentos, o por contratos y no solo entre nosotros, sino pasando a individuos que no consideramos de nuestra raza. Este es un hecho que aparte de poderse registrar en los protocolos de los escribanos es patente si se considera que al consumarse la independencia, los indígenas tenían doble extensión de tierras de las que hoy pueden poseer.

En el siguiente párrafo de nuevo se está traduciendo una realidad local a los términos del Estado o de las leyes nacionales, ya que las empresas (compañías), sociedades o asociaciones sí eran permitidas e incluso promovidas por el gobierno nacional. Se argumenta desde la práctica, desde lo que existe, es decir desde los hechos (de facto) y se contrapone este modelo de sociedad al modelo ideal de sociedad (pero alejado de la realidad) que se pretendía implantar.

Véase pues bajo este aspecto nuestra comunidad; considérese tal como es, una compañía, y se comprenderá; primero, que en el ejercicio de nuestros derechos hemos podido establecer una sociedad para el cultivo de nuestros terrenos, contando para ello o con los recursos de cada individuo o con los del fondo común, siendo esto uno de los contratos reconocidos y protegidos por la ley; segundo, que así constituidos los indígenas, ni ellos quedan obligados, como antiguamente lo eran por los tribunales, ni menos perjudican a la sociedad, pues son libres para entrar como de facto entran, al comercio general, pudiendo ser demandados conforme a la legislación común y señalarse sus bienes en pago de las deudas que hayan contraído; y tercero, que hay cierta injusticia dimanada de la coerción que se ejerce en nosotros, al obligarnos con la fuerza al repartimiento de nuestros terrenos que con gusto y por unánime acuerdo estamos cultivando en común. Y decimos que por la fuerza, porque lo es y poderosa la amenaza que se nos 
hace de que pasando un año serán adjudicables nuestros bienes raíces como lo fueron los llamados eclesiásticos.

Si así sucediera, lo mismo y con igual razón, podrá acontecer a todos los que forman parte de una sociedad universal.

Una declaración de esta naturaleza vendría a sellar el cúmulo de desgracias que han pesado sobre nosotros desde 1521 . De entonces a acá hemos sido víctimas, primero de los conquistadores, que se apropiaron la mayor parte de nuestro territorio y después del clero que bajo el pretexto del culto nos tomaba los mejores de nuestros terrenos. ¿Y nos veríamos hoy en virtud del decreto del 9 de Diciembre del año pasado seducidos dentro de poco tiempo a la miseria y acaso a la mendicidad?

Estamos convencidos de que el único pensamiento de esa ley es el deseo de nuestro mejoramiento, a la vez que el adelanto de la sociedad nuestra experiencia nos enseña que lejos de producir tan saludables ejemplos no hará más que pasen en la misma triste situación de los pueblos que ya se han repartido a los que tenemos la fortuna de conservar aún nuestros terrenos.

Por esto venimos a Usted C. Gobernador confiados en que se identificará con nosotros e iniciará ante la Legislatura una providencia en que se nos considere como sociedades, derogándose la ley que nos impone el reparto, bajo el concepto de que nosotros mismos estamos persuadidos de que ni por las leyes ni por el espíritu de la época puede subsistir el sistema de comunidades.

Por tales términos:

Pedimos se digne acordar favorablemente este escrito, en lo que recibiremos distinguida merced. ${ }^{7}$

Aparece claro el reconocimiento de los valores universales que emanan de las leyes nacionales a condición de que también se les reconozca a ellos su modernidad ("se nos considere como sociedades”). Admiten que no pretenden los privilegios de antaño, pero que dentro de la legalidad se les reconozca como sujetos particulares, sometidos a las leyes nacionales.

${ }^{7}$ Morelia, Marzo 8 de 1869. Firman: los comuneros mencionados al inicio del documento (AGHPEM, hijuelas, libro 12, fojas 26-28) 
En 1869, más de veinte apoderados y comisionados de 16 comunidades presentan un documento en el que utilizan las concepciones de ciudadanía, territorio (posesión comunal) y autoridad reconocida, además de prácticas de usos y costumbres. También señalan que existe un problema de comunicación y/o desconocimiento en las "comunidades" de los supuestos "beneficios" de la nueva legislación. Además como lo demostrarán fehacientemente los reclamos de restitución de prácticamente todas la excomunidades durante la primera mitad del siglo xx, los indígenas o pueblos indígenas no entendían ni estaban convencidos de las bondades de la propiedad particular e individual. Se destacan y ofrecen argumentos de carácter cultural e histórico, de tiempo y falta de recursos y se hace énfasis en las desigualdades existentes y en su agudizamiento en caso de que se realice el reparto. Se reconoce el uso particular, individual o si se quiere familiar de las propiedades pero bajo un claro esquema legal de carácter comunal. Esta situación jurídica seguirá siendo reivindicada e incluso fortalecida prácticamente durante todo el siglo xx.

En primera instancia aceptan el reparto y reconocen la tarea de los legisladores y del gobierno y sin embargo dadas las dificultades solicitan más tiempo para realizar el reparto. Luego, apelan a la costumbre y al conocimiento acumulado para argumentar las bondades de mantenerse en comunidad. El documento además contiene también todo un planteamiento acerca de los procedimientos que idealmente se deberían seguir para lograr un reparto efectivo.

\section{Gobernador:}

Mariano Velásquez, Prudencio Ramírez, Francisco Velásquez, Abraham Molina [y 22 nombres más] apoderados los siete primeros de las comunidades de Zacán, Zirosto, Paracho, Cherán, Nahuatzen, Tancítaro, Apo y Peribán, y comisionados los otros de las de Paricutín, Pamatácuaro, Angahuan, Aranza, Sevina, Corupo, Parangaricutiro, y Tinguindín, por el ocurso que sea más legal y con el debido respeto ante usted comparecemos y decimos: que las providencias que en cumplimiento de la ley del 9 de Diciembre del año anterior se han dictado para hacer efectivo el reparto de los terrenos de comunidades, han causado grande agitación en los pueblos en cuyo nombre elevamos al presente ocurso. Si hubiésemos de aten- 
der exclusivamente a sus deseos, debiéramos dirigirnos a la Legislatura del Estado solicitando la erogación de la ley que les prohíbe continuar en comunidad y que les impone como obligatorio el reparto de sus propiedades. Acaso no faltarían buenas razones en qué fundar esta solicitud, pero han sido ya examinadas y discutidas en diversas épocas encontrándose siempre como más conveniente al interés público y particular de los indígenas el reparto de los terrenos de comunidad. Los que representamos, respetan pues esta decisión no quisieron de ningún modo frustrar las miras del legislador, y a pesar de su deseo de continuar en comunidad se han resuelto a solicitar puramente que se les otorgue un plazo competente para verificar el reparto de sus terrenos de una manera provechosa y con las dificultades con que ahora tropiezan para llevarlo a cabo. Esta pretensión les parece del todo justa; pero para mejor apoyarla, nos permitiremos exponer las razones en que se funda.

Hemos manifestado ya que la generalidad de los indígenas vería con gusto la continuación de las comunidades. Acostumbrados a ellas por un largo periodo de tiempo, no les es fácil prescindir en un momento dado de los hábitos y costumbres de muchos años. Una especie del instinto fortificado con la observación de lo que han visto en otras comunidades cuyos bienes se han repartido, les dice que el reparto de sus terrenos será la ruina de sus pequeñas propiedades y los dejará reducidos a la triste condición de extraños en sus posesiones sujetas o comprar en ellas, lo que antes disfrutaban como dueños. Su corta capacidad y la ignorancia en que desgraciadamente viven, no les permite conocer las ventajas que pueden esperar de un reparto hecho en justicia, ni los pone en aptitud de aprovechar los beneficios que el legislador quiere proporcionarles con la destrucción de las comunidades. Lejos de esto ven en ella un mal y la resisten por los medios que están a su alcance. Esta resistencia es un inconveniente de gravedad para llevar a cabo el reparto de una manera conveniente y expedita, pues de ella nacen dificultades prácticas que se perciben por sí solas, y que por lo mismo no necesitamos hacer presentes. Preciso es por esto que antes de verificar el reparto se vaya generalizando entre los indígenas el convencimiento de su conveniencia y necesidad, para que aceptándolo con gusto, o a lo menos sin contradicción, pueda verificarse expeditamente, sin dificultades prácticas y sin agitaciones en las comunidades. La difusión de este convencimiento es una medida previa y necesaria para la destrucción de 
las comunidades y como no puede lograrse desde luego, ella por sí sola funda nuestra solicitud.

La concesión de un término prudente para llevar a cabo el reparto de los terrenos de indígenas es también necesaria para que esta medida produzca a favor de aquellos los benéficos resultados que de ella se esperan. Mientras los indígenas no sepan apreciar las ventajas de que goza el pequeño propietario, el reparto será para ellos nocivo y ruinoso. No estimando la propiedad territorial por las ventajas que proporciona, la fracción que a cada uno toque en el reparto de su comunidad, será en sus manos un valor improductivo, más bien gravoso, y subestimará a deshacerse de él quedando en una situación peor de la que guardaría si hubiese continuado en comunidad. Así ha sucedido efectivamente en algunos pueblos de indígenas en que los repartos se han hecho violentamente y así lo han comprendido de las leyes de la materia cuando han prohibido a los indígenas vender sus terrenos dentro de un periodo dado de tiempo. La experiencia ha demostrado que esta prohibición ni puede subsistir ni basta para su objeto y por lo mismo que el remedio del mal que se propuso evitar debe buscarse por otros medios. El más a propósito, quizá el único, es el de hacer que los indígenas sepan apreciar las ventajas de la propiedad, pues sólo así la estimarán y sabrán conservarla y servirse de ella en provecho propio. Esto demanda también el transcurso del tiempo y prueba por lo mismo la necesidad de conceder nuevo término para que verifique el reparto de las tierras de comunidades de indígenas.

Fuera de estas reflexiones generales, hay otras que fundan nuestra solicitud por la imposibilidad que hay de hacer el reparto en el corto tiempo que falta para que concluya el término que señaló la ley del 9 de diciembre último. Antes de proceder al fraccionamiento de los terrenos de comunidades es preciso como en toda división, convencer y determinar perfectamente los terrenos que deben dividirse. Los de comunidades están en la generalidad en litigio ya con los propietarios colindantes, ya con otras comunidades, y aún los que no se hayan en este caso, no tienen sus límites perfecta y exactamente determinados o porque no están reconocidos o porque el tiempo los ha confundido. $\mathrm{Al}$ reparto debe, pues, proceder la conclusión de los litigios pendientes y el amojonamiento de los terrenos repartibles, pues de otra manera las operaciones del reparto no serían definitivas, quedando sujetas a las modificaciones que fuese necesario hacer en 
ellas según el resultado último de los litigios y amojonamientos. Esto producirá graves dificultades en la práctica, pues al hacer más modificaciones volverían a suscitarse todos los inconvenientes ya vencidos, porque realmente sería necesario practicar un nuevo reparto aumentando o disminuyendo la porción que en el primero hubiese tocado a cada uno de los porcioneros. En muchos casos sería imposible conservar la continuidad de las fracciones, que tan conveniente es procurar, porque dando el litigio por resultado preciso la agregación o segregación de un terreno determinado, sobre este deberían recaer las nuevas operaciones de reparto y sería preciso para no destruir las anteriores, verificar aquellas sin tener en consideración éstas, resultando de todo un reparto verdaderamente monstruoso. Además las nuevas operaciones que hubieran practicarse forzosamente originan nuevos gastos que gravarían a las comunidades erogándolas por segunda vez. Si pues, se quieren evitar estos inconvenientes, es necesario que al reparto proceda la conclusión de los litigios pendientes y el amojonamiento de los terrenos repartibles y por lo mismo que se conceda a las comunidades un término pendiente para que dentro de él practiquen estas operaciones previas e indispensables.

Tanto ellas como el reparto demandan gastos de algunas consideraciones que la pobreza de las comunidades no les permite erogar desde luego. La venta de algunos terrenos con el objeto de cubrir gastos no sería conveniente bajo ningún aspecto en los momentos en que va a hacerse el reparto. El número de los individuos o familias entre quienes debe hacerse es grande y por muy extensos que se supongan los terrenos de algunas propiedades, siempre quedarán divididos en fracciones demasiado pequeñas y que serían verdaderamente insignificantes si los terrenos se disminuyen por la venta de alguna porción para erogar los gastos que indispensablemente demanda el reparto. Hay entre los solicitantes alguna comunidad cuyos terrenos tienen un valor de ciento cincuenta pesos y que desaparecerían si con ellos hubieran de hacerse los gastos del reparto. En esta virtud todas las comunidades desean proporcionarse por algún otro medio los recursos con que han de acudir a los gastos repetidos, y no teniéndolos de pronto se ven en el caso de solicitar también por esta razón la concesión de un nuevo plazo para verificar el reparto.

Estas son sustancialmente las razones que fundan nuestra solicitud [...] Fiados en ellas y en la paternal solicitud con que el Supremo Gobierno ha 
visto siempre a la desgraciada clase indígena, esperamos que nuestra solicitud será atendida concediéndose el nuevo plazo que pedimos y librando las órdenes correspondientes a los Ciudadanos Prefectos para que cesen de instar a las comunidades para que procedan al reparto de sus terrenos, absteniéndose de molestar a los indígenas con multas y prisiones como lo han hecho ya algunos de ellos. Juzgamos que siendo nuestra solicitud arreglada a justicia no habrá inconveniente para que se acuda a ella y en tal virtud a usted pedimos que si estuviere en sus facultades se sirva conceder a las comunidades de indígenas el término de dos ańos para que dentro de él hagan el reparto de sus terrenos o en caso contrario elevar este ocurso a la Legislatura del Estado para que tomándolo en consideración se sirva acceder a nuestra solicitud, en lo que recibiremos señalada merced y gracia. ${ }^{8}$

Los problemas de la falta de recursos, la estrechez de los tiempos y la indefinición de los límites mantendrán su vigencia prácticamente hasta nuestros días e impedirán durante toda la época moderna de México que se adopte plenamente la propiedad privada y que se formalice su uso en las denominadas excomunidades indígenas.

\section{El problema de los limites}

Puede observarse como conforme transcurre el tiempo, sin que se solucionen los conflictos intercomunales y la definición de límites, el discurso comunalista se va enraizando en las llamadas "excomunidades". Tal es el caso clásico de las disputas entre Nurío, Cocucho y San Felipe de los Herreros, estudiado, entre otros, por Bello (2007). También el caso de Nahuatzen resulta particularmente interesante porque según lo que se puede observar de las hijuelas mantenía varios conflictos por límites que le impedían la conclusión del reparto agrario. Todavía en 1895, manifestaba el apoderado de los indígenas "condueños" que no habían podido realizar el reparto por causa de los varios litigios que mantenían con las comunidades vecinas.

${ }^{8}$ Morelia, Junio 12 de 1869 ”. Firman: Todos los apoderados de las comunidades inicialmente mencionadas (AGHPEM, hijuelas, libro 21, fojas 41-44). 
Sin que se tuviera claro quien era el dueño de un terreno, simple y sencillamente no se podía proceder a repartir, dividir o liquidar como lo muestra el siguiente documento.

\section{Ciudadano Gobernador:}

José $\mathrm{F}$. Guido personero de los indígenas condueños de las tierras que fueron de la extinguida comunidad del pueblo de Nahuatzen, Distrito de Uruapan, [...] me presento a exponer que mis poderdantes no habían podido obsequiar las varias disposiciones dictadas sobre repartimiento de tierras de excomunidades de indígenas, entre otras causas, por la muy poderosa de su deseo de concluir varios litigios que con pueblos vecinos tienen pendientes sobre propiedad de tierras: que algunos de esos litigios están ya concluidos y aunque otros están muy distante de serlo, mis propios representados se han resuelto a verificar la participación de las tierras de labor y montes de que se hallan en legítima posesión dejando a salvo sus derechos respecto de todas aquellas que no poseen por haberles sido usurpadas. Morelia, Octubre 22 de 1895. Firma: José Trinidad Guido.

(АGHрем, hijuelas, libro 3, foja 178).

Otro ejemplo es la comunidad de Tanaco y sus conflictos limítrofes con prácticamente todos sus vecinos. Ante esta situación apelan al supremo gobierno como árbitro imparcial, pero además interesado en mantener el orden y lograr el reparto, para que intervenga y termine con los conflictos.

\section{Señor Gobernador}

[más de cien nombres]; todos indígenas y vecinos de este pueblo, ante Usted por medio del presente ocurso, pasamos a exponer; que conforme a nuestros títulos, somos dueños de una extensión de terreno como de diez y ocho kilómetros ochocientos cincuenta y cinco metros cuadrados, según cálculo más o menos aproximado, entre montes y prados, de cuya propiedad estamos pagando las contribuciones correspondientes [...] De la extensión referida, nos han usurpado los indígenas de Urén y de Cheranatzicurín, una de un kilómetro cuadrado los primeros y los segundos como tres [...] Por el lado sur, tienen los de Aguiran como quinientos metros cuadrados y otros tantos los de Urapicho por el rumbo sur-oeste, sólo de 
monte. [...] Aunque esta circunstancia habló muy alto a favor de nuestra causa, permanecimos algún tiempo indecisos, y al fin nos resolvimos a continuar el juicio al cual los denunciados no se presentaron y desistimos de seguirle el juicio en rebeldía, por lo interminable de los trámites judiciales como por falta de fondos. Estos mismos motivos nos han obligado a no intentar reclamaciones a los demás pueblos, esperando que el tiempo y las disposiciones del Gobierno, vayan a terminar las diferencias que sobre terrenos existen en este pueblo y en otros que se encuentran en las mismas condiciones. El plano que definitamos dará a Usted una idea más o menos cierta de la situación topográfica de nuestro pueblo y de los límites que constan en su explicación. No pudiendo resolvernos a dejar que los pueblos colindantes continúen aprovechándose de lo que nos pertenece, hemos acordado hacerlo saber al Gobierno del digno cargo de Usted, a fin de que, si lo estima de justicia, se sirva allanar estas dificultades, de tal manera que su resultado venga a establecer entre nosotros la paz y quietud con nuestros vecinos y cesen las invasiones y tropelías que a mano armada cometen los de Urén y Cheranatzicurín impidiéndonos el libre uso de nuestras propiedad rural, bajo pretexto de que pertenece a ellos. Si en nuestra República ha habido un hombre que ha podido establecer la paz entre sus habitantes, de la cual estamos disfrutando hace como veintisiete años ¿̨por qué en una insignificante fracción de ella no se ha de poder remediar el mal estado que guardan algunos pueblos de indígenas por diferencias de límites en sus propiedades? Por qué el Supremo Jefe del Estado no se resuelve a dictar sus sabias y prudentes determinaciones gubernativas para que se fijen los linderos a cada pueblo y una vez conocida cese la incertidumbre que nos aborela a un pleito a mano armada, por mantener la integridad de nuestros terrenos hasta donde los títulos nos dicen "Hasta aquí es los tuyo" Esperamos pues que su Supremo Gobierno atienda nuestra exposición dictando oportunamente las disposiciones convenientes, tanto para beneficio nuestro en particular, como el de los otros pueblos de esta región que se hallan en iguales circunstancias, y se faciliten las operaciones de reparto de la propiedad común, sin obstaculizar que vengan a interrumpir o a suspender los procedimientos. Como lo que dejamos dicho es en nuestro concepto un asunto de grande importancia.

Suplicamos se sirva atender y ver con el interés que se merece el presente ocurso, en lo cual recibiremos justicia. 
Tanaco, Agosto 20 de 1903. Firman: Rafael Álvarez, Refugio Álvarez, Guadalupe Bravo y decenas de nombres de indígenas de Tanaco.

(AGHPEM, hijuelas, libro 12, fojas 58 y 59).

El discurso sobre la ocupación desde tiempo inmemorial de las tierras está también presente en los alegatos con respecto al reparto de tierras. En 1896, Manuel Ibarrola, apoderado de los porcioneros de Pichátaro alega que

[sus ponderantes] desde tiempo inmemorial han estado en posesión quieta y pacífica de una extensión de tierras que tendrá más o menos tres sitios de ganado mayor, y linda por el oriente con tierras de Porumbo y Carichero, por el Poniente con propiedades del pueblo de Comachuén y Sevina, por el Norte con terrenos de Coyote y Zinciro, y por el Sur con tierras del pueblo de Tingambato.

\section{Y alega que no han podido realizar el reparto}

muy especialmente por los varios litigios que han tenido que sostener con los pueblos vecinos para defenderse de las invasiones de que han sido víctimas; pero convencidos de la necesidad de repartirse los terrenos que poseen pacíficamente y sin reclamación alguna, y reservándose sus derechos respecto de los terrenos que tienen en litigio con los pueblos de Comachuén, Nahuatzen y Sevina, por mi conducto solicitan de esa Superioridad, se les autorice para proceder al reparto de las tierras de que son poseedores, dictándose todas las medidas que fueren oportunas.

En este caso, la respuesta de la Secretaría de Gobierno aceptando la propuesta del apoderado fue inmediata, ya que sus representados estaban "convencidos" de que recibirían mayores beneficios si se reparten, por lo que se dan indicaciones y se propone el formato que se debería de seguir para la realización del reparto. ${ }^{9}$

9 "manifestando, además, el solicitante [se refiere a Ibarrolla] que su gestión tiene por origen el convencimiento que han adquirido las personas que representa, de que reciben mayores beneficios de que cada uno reconozca una parte determinada de terreno, que de la indivisión, y que si antes no habían hecho esa solicitud, ha dependido de que tenían 
Sin embargo dos meses después prácticamente se suspenden los trabajos del reparto por el conflicto por límites que Pichátaro tenía con Nahuatzen. Supuestamente este último pueblo había realizado el reparto 20 ańos antes y era citado como uno de los primeros que lo realizó. Al parecer lo que suscitó el conflicto fue la explotación de madera, que según el apoderado de Pichátaro los de Nahuatzen de manera ilegal estaban haciendo. Por lo que solicitan se suspendan los trabajos tanto de reparto de tierras (por el litigo que tienen pendiente) y de corte de madera porque todavía no se adjudican esos terrenos a ninguna comunidad. ${ }^{10}$ Las historias se continúan hasta la actualidad,

litigios pendientes con pueblos limítrofes, sobre determinación de la línea divisoria de sus propiedades.

La Sección propone salvo siempre el respetable proceder el Ejecutivo, que, accediéndose a la petición expresada, se dicten desde luego las órdenes conducentes al nombramiento de comisión repartidora y las relativas a que se ejecuten los trabajos preliminares, que se reducen a formar las tres piezas que constituyen las bases del reparto, y son: el padrón general de accionistas, el croquis de las tierras repartibles y el presupuesto de gastos que se calcule erogar en las operaciones indicadas y en las subsecuentes hasta poner a los indígenas en posesión de los lotes que se les señalen. A este efecto podrían darse las instrucciones que se acostumbra dar en casos análogos [a continuación enlista los procedimientos que se deberán seguir, como hacer el padrón, el plano, la comisión, etc. y que son similares a los recomendados a los otros pueblos] Sección 4a de la Secretaría de Gobierno". Morelia, Enero 30 de 1896. Firma: Gabriel Ávila (AGHPEM, hijuelas, libro 21, fojas 115-117).

${ }^{10}$ C. Gobernador del Estado.

"Manuel Ibarrolla, apoderado de los porcioneros de Pichátaro expongo:

Mis poderdantes tienen en litigio con los del pueblo de Nahuatzen una grande extensión de terrenos, que comienza en el monte de Capuen Hurumbarapio, Angamandiro, Cruz de Caratacuaro, hasta la falda del cerro del Chivo, y en ese punto, a pesar de que la posesión favorece a los de Pichátaro, últimamente los de Nahuatzen bajo el pretexto de reparto han comenzado a cortar gran cantidad de madera, y han ejercido violencias sobre Macario González, Gonzalo García y Mateo Espinoza, que trataban de impedir el corte de madera.

La práctica constante de esa Superioridad en casos semejantes, es suspender los trabajos que de alguna manera revistan el carácter de atentatorios, y tal suspensión me parece procedente en el caso, porque los terrenos en que los de Nahuatzen andan ejecutando los actos que acabo de referir, están en litigio con el pueblo de Pichátaro, y no se han definido los derechos.

Me parece oportuno poner en conocimiento de esa Superioridad que está en arreglos con el apoderado de Nahuatzen para terminar por medio de una transacción las diferencias que hay con el pueblo a quien represento, pues que dado el carácter de los indígenas sólo de esta manera terminará el litigio que ha venido impidiendo en gran parte el reparto de los de Pichátaro.

A Usted pido dictar acuerdo suspendiendo los trabajos de corte de madera y demás que andan ejecutando los porcioneros de Nahuatzen, librando sus superiores ordenes para que se cumplan". 
quedando pendientes en muchos casos, la resolución de los problemas limítrofes entre comunidades. Lo que permitió que al interior de las excomunidades se fortaleciera la idea de la imposibilidad del reparto y de la titulación a particulares de los bienes de comunidad.

\section{La defensa de los bosques}

A finales del siglo XIX aparece un elemento más que vendrá a complicar el proceso de privatización de tierras y evidenciar la necesidad de que las comunidades mismas controlaran sus bienes comunales.

La extrema explotación del bosque, que ya estaba ocurriendo, era resultado, tanto de la acción de algunos apoderados que a su libre arbitrio enajenaban y vendían grandes cantidades de árboles, como una clara manifestación de los conflictos y divisiones internas ya que generalmente aparecen algunos grupos locales más interesados en repartir y vender los productos del bosque que en conservarlos. Frente a esta situación algunos grupos alertaban sobre el grave peligro que eso significaba para las comunidades, amenazando no sólo su existencia misma sino que no pudiera concluirse el reparto y que por consiguiente sus efectos fueran lo contrario a lo que el gobierno buscaba con las reformas liberales.

Los argumentos más claros aparecen en el alegato que un grupo de indígenas de Nahuatzen hacen al gobierno del estado y en los que de nuevo aparece la preocupación por su seguridad y reproducción social:

\section{Gobernador del Estado}

Los que suscribimos, indígenas vecinos de Nahuatzen [...] manifestamos: que $[\ldots]$ hemos solicitado el reparto de algunos terrenos poblados de árboles de pino, que hay sin aplicarse a los porcioneros, porque se apartaron para astillero común cuando se hizo un reparto hace como veinte años.

El objeto que tuvimos al separar dichos montes, fue el de que los indígenas pobres tuviésemos de donde tomar madera para nuestros usos ordinarios, convencidos como estábamos de que si se dividían tales terrenos,

Morelia, marzo nueve de 1896. Firma: Manuel Ibarrolla.

(AGHPEM, hijuelas, libro 21, foja 120). 
serían vendidos luego a los extraños del pueblo, y después no querrían darnos ni un palo para quemar y careceríamos de un artículo tan necesario en estos climas fríos; pero viendo que el monte se estaba acabando ya, y que pronto nos quedaríamos sin madera, resolvimos pedir el reparto [...]

Los cortes de madera siguen con mucho empeño, y abrigamos el temor de que antes de que se haga el reparto, haya desaparecido el monte, y sin los árboles de pino nada valen los terrenos, pues son ladera de cerro y de tierra muy delgada e inútil para las siembras. Además con la falta de vegetación, está disminuyendo, de una manera alarmante el manantial que surte de agua a la población, y no sabemos en qué se invierte el producto de la venta de la madera: hay muchas personas que han comprado fuertes cantidades de carretadas de vigas, y nada útil se hace aquí. La escuela de nińas que se proyectó construir todavía no se concluye: están sólo las paredes y la cubierta y esto costó al pueblo cuatrocientos cincuenta pesos, habiendo dado los vecinos la madera y el tejamanil y acarreado los adobes. Estos son los hechos, como lo sabrá el Gobierno, si manda a practicar la averiguación necesaria.

Por lo mismo A Usted C. Gobernador, recurrimos para pedirle muy humildemente que se digne ordenar que no se sigan destruyendo los bosques de estas sierras, haciendo talas tal inconsideradas como está sucediendo; pues si se llevan a efecto algunos contratos que sabemos han celebrado los apoderados, es seguro que nos irán a repartir tierras sin ningún valor y tal vez nos quedemos sin manantial, o con una pequeńísima cantidad de agua. También suplicamos a usted que no se pida informe al Ayuntamiento, de este pueblo, porque dos o tres regidores están negociando con el monte, y el secretario es el director de los apoderados, y con toda seguridad se negarían los hechos, se les daría otro colorido, o se diría que los apoderados han vendido con facultad para gastos del pueblo. Por otra parte, seríamos víctimas de las arbitrariedades de los que por aquí mandan, y nos causarían muchos males. Si al Sr. Prefecto del Distrito le fuera posible venir sin anunciarse, y tomara informes de personas honradas y de los buenos vecinos del lugar, podría descubrir, algunos abusos y vería el destrozo que se está haciendo en los montes. Protestamos obrar de buena fe y en defensa de nuestros derechos.

Nahuatzen, enero 10 de 1896. Firman: Alejo Villa y Luis Huerta.

(AGHPEM, hijuelas, libro 3, fojas 183-184) 
En el documento anterior destaca también la queja contra el ayuntamiento mismo al que acusan de "negociar" con su monte. También es de resaltar que los argumentos que esgrimen los indígenas están dentro de la lógica del mercado, es decir, se argumenta que son tierras que nada valen y si no se cuida el bosque que es de lo poco valioso perderán todo su valor. Esta queja contra las autoridades locales, nos muestra la importancia de la diferenciación interna y de las contradicciones entre quienes pretendían capitalizar y explotar el bosque y aquellos con un discurso comunalista y hasta cierto punto ecologista. También por supuesto, la falta de homogeneidad al interior de la comunidad y la importancia de las contradicciones (o de los proyectos encontrados) que señaló Roseberry como factor determinante en la ejecución o no del reparto agrario.

El problema de la explotación del bosque sin duda fue una de las preocupaciones principales de los habitantes de Nahuatzen, de tal manera que en 1896 se levantó un acta en la que se nombra al nuevo comisionado para que reparta los ejidos "tomando por base la lista de los indígenas que se formó en 1873" "habían pasado más de veinte años] finalmente antes de concluir la asamblea uno de los participantes señaló "que a efecto de evitar los perjuicios que se le están siguiendo a la excomunidad con la excesiva venta de la madera, pide al Gobierno libre eficaces ordenes para que se violente el reparto: esta petición fue secundada por los indígenas". ${ }^{11}$ Es decir,

11 "En el pueblo de Nahuatzen a las tres de la tarde del día ocho de enero de mil ochocientos noventa y seis, reunidos el C. Silviano Martínez, Prefecto del Distrito de Uruapan, en la sala de acuerdos del ayuntamiento, así como también estando presentes los indígenas del mismo lugar [...] se le dio lectura a dicho oficio, en que de acuerdo con la solicitud del Sr. Lic. José Trinidad Guido, el Gobierno dispuso el reparto de los terrenos que eran montańosos en 1872 y el pequeño cerro que fue repartido para ejidos, tomando por base la lista de los indígenas que se formó en el año de 1873 en la forma y términos que se indican en la nota de que se trata. En segunda, el Sr. Prefecto interrogó a dichas personas sobre a quien comisionarían para practicar las operaciones del reparto y contestaron: que por reunir los requisitos de honradez e imparcialidad el C. Encarnación Román, vecino de esta población, lo designaban para que hiciera dichos trabajos [...]

Encontrándose presente y en la junta el Sr. Encarnación Román, dijo: que acepta de buena voluntad la comisión que los indígenas pretenden darle, y que para proceder a los trabajos de su cometido sólo espera la resolución del Gobierno bajo el concepto de que por lo que toca a la remuneración de los indicados trabajos recibirá la que los mismos indígenas con aprobación superior; en justicia le señalen. Para concluir tomó la palabra 
que se detuviera dado los dańos que ya se estaban causando al medio ambiente y posiblemente al visible enriquecimiento de unos cuantos a costa de los bienes de la excomunidad, que idealmente seguía existiendo.

La siguiente cita vuelve a hacer referencia a la solicitud de intervención del gobierno para que se suspendan los cortes de madera:

\section{Prefecto de Uruapan}

Varios vecinos del pueblo de Nahuatzen han dirigido al Gobierno la solicitud que se mande suspender el corte de madera que saben tienen vendidas de los montes de aquel lugar, los apoderados de los indígenas, con lo cual, los peticionarios reciben graves perjuicios en los intereses de la excomunidad del mismo pueblo [...]

Morelia, enero 22 de 1896. Firma: L. B. Valdés.

(AGHPEM, hijuelas, libro 3, fojas 189).

Frente a esta petición, la respuesta del gobierno es de alguna manera la de "lavarse las manos" y dejarle la responsabilidad a los mismos indígenas para que defiendan sus propios bosques, es decir, cederles cierta autonomía, misma que en otras ocasiones lo único que había provocado eran enfrentamientos violentos. Curiosamente parecería una respuesta clásica de un gobierno liberal que se niega a intervenir.

\section{Prefecto de Uruapan.}

Se ha impuesto el Gobernador del estado del informe que rinde Ud. en oficio núm. 66 acerca de la solicitud de los indígenas de Nahuatzen que se suspendiese el corte de maderas vendidas por los apoderados.

Manifiesto a Usted, por acuerdo del mismo funcionario, que el Gobierno procurará se active el reparto en cuanto sea posible y que se apruebe la determinación de la Prefectura de no haber suspendido el corte de ma-

el C. Luis G. García, y dijo: que e efecto de evitar los perjuicios que se le están siguiendo a la excomunidad con la excesiva venta de la madera, pide al Gobierno libre eficaces ordenes para que se violente el reparto: esta petición fue secundada por los indígenas. Para constancia de lo ocurrido en la junta se levanta por duplicado la presente acta que firman con el Sr. Prefecto las personas que saben hacerlo. Doy fe. Firma: Silviano Martínez y muchas firmas más" (AGHPEM, hijuelas, libro 3, fojas 186-188). 
deras, porque no corresponde a la autoridad administrativa dictar medidas, como la que se trata.

Ya se dijo a los peticionarios que de ellos y no del Gobierno, depende evitar los abusos de los apoderados, limitándoles las facultades que les tienen dadas, exigiéndoles cuentas de la inversión de los productos de los bienes que tienen a su cuidado, retirándoles, si fuese necesario el poder conferido, o dándoles nuevas instrucciones para el ejercicio del mandato, pues cualquiera de los procedimientos indicados, bastará para impedir los, perjuicios que, dicen los indígenas de Nahuatzen, están siguiendo sus intereses.

Convendrá que la Prefectura insista sobre este particular advirtiendo a los indígenas que ejerciten sus derechos de una manera pacífica y ordenada y que la autoridad les prestará el apoyo que corresponda para ese ejercicio.

Morelia, enero 31 de 1896.

(AGHPEM, hijuelas, libro 3, foja 191).

En ese mismo año de 1896, los indígenas de Nahuatzen insisten en que se detenga el reparto de tierras en virtud de los dańos que se le están ocasionando a los bosques de la excomunidad a lo cual el secretario de Gobierno del Estado de Michoacán, sorpresivamente responde al prefecto de Uruapan que la queja no carece de fundamento

En respuesta al oficio [...] tengo la honra de manifestarle que con motivo de la junta de indígenas que se verificó en el pueblo de Nahuatzen para que designaran la comisión que se encargara del reparto de los bienes que poseen en común, algunos de los mismos indígenas dijeron que deseaban se violentaran las operaciones del reparto, en virtud de que se estaban haciendo verdaderos destrozos en los montes sin provecho ni voluntad de los dueńos $[\ldots]$

Posteriormente $[\ldots]$ se me presentó un grupo de más de cincuenta indígenas reiterando su solicitud de que se violentara el reparto por la razón antes dicha y todavía más, que el que suscribe mandara suspender el corte de madera. A lo primero contesté que ya se daba conocimiento al Gobierno de la petición, y a lo segundo, que no estaba en las facultades de la autoridad política mandar suspender el corte de madera, pues esto entre otras consideraciones por haber contratos de por medio, sólo podía ordenarlo la judicial a quien los interesados podían acudir con tal objeto. 
Excusado me parece manifestar a Usted que me inclino a creer que la queja de los indígenas no carece de fundamento, pues esa Superioridad sabe perfectamente cuál es la conducta que observan, si no todos la mayor parte de los apoderados de las comunidades, especialmente si sirven en los pueblos pequeños, en donde su ascendiente sobre los indígenas es absoluto.

Libertad y Constitución. Uruapan, enero 21 de 1896. Firma: Silviano Martínez, Secretario de Gobierno.

(AGHPEM, hijuelas, libro 3, foja 192).

Hacia 1901 y por causa de las divisiones internas y los problemas suscitados por la explotación del bosque no se podía concluir el reparto en la excomunidad de Nahuatzen. El siguiente escrito es otra evidencia de las divisiones internas y de que éstas fueron sumamente importantes en la definición de los procesos que estaban en marcha, según el comisionado legal para el reparto de las tierras del pueblo, Encarnación Román exponía lo siguiente:

por razones que no son del caso referir, no se han podido terminar los trabajos de dicho reparto, y ya varios porcioneros que recibieron fracciones en el cerro "Capen" de esta pertenencia, las han vendido con el monte [...] a diversas personas por un valor ínfimo, cuyo perjuicio no se ha podido evitar, siguiendo así las ventas y siendo los vendedores la clase más pobre.

Por otra parte, las mismas personas compradoras han estado mandando labrar madera sin moderación en dichos lotes y algunas de ellas están haciendo desmontes y potreros siendo esto otro de los mayores perjuicios por las condiciones higiénicas y también para los indígenas que no prevén los graves males que pronto han de sobrevenir por la destrucción de árboles; y aunque la autoridad política de este municipio ha querido impedir las ventas de terreno y monte de que hago mérito, no lo ha podido conseguir.

Por lo expuesto C. Gobernador suplico que tomándolo en consideración, se digne determinar lo que en el respetable concepto de usted sea conveniente para que no se sigan vendiendo las fracciones de terreno de que se trata y que no pasen por venta las que antes fueron vendidas por no estar en el [...] Y en cuanto a los demás perjuicios que se ocasionan, Usted se dignará acordar lo que a bien tenga. 
Con lo que se reciba cumplida justicia.

Nahuatzen, febrero 12 de 1901. Firma: E. Román.

(AGHPEM, hijuelas, libro 3, foja, 203).

Esta parte del expediente de Nahuatzen concluye con la indicación del gobierno del estado para que se realice una averiguación escrupulosa para posteriormente dictar las providencias convenientes, dado que la tala del monte ha ocasionado "graves prejuicios a los intereses públicos" y en particular a los de la excomunidad "por el estorbo que esas ventas pondrán a la conclusión de las operaciones del reparto". ${ }^{12}$ Finalmente el gobierno del estado reconoce que debe tener una participación más directa en el manejo del bosque y por consiguiente limitar el reparto indiscriminado en función del bien público.

[...] Respecto de los montes de Tanaco, aún no se procederá a su fraccionamiento, pues el Gobierno está meditando en un proyecto que se encaminará a impedir que por medio de los repartos se destruyan los bosques del Estado por el perjuicio que resulta a los intereses públicos.

Morelia, Agosto 27 de 1902.

Firma: M. G. Real.

(AGHPEM, libro \#12, s/n foja).

${ }^{12}$ C. Prefecto de Uruapan

"El Señor Encarnación Román, comisionado para perfeccionar el reparto que desde el año de 1874 se practica en los terrenos montuosos pertenecientes a lo extinguida comunidad de Nahuatzen, ha hecho un ocurso al Gobierno, manifestando que los porcioneros a quienes se han señalado lotes, están vendiendo la madera que en ellos se encuentra y varios comprenden también el terreno mismo, resultando de esto graves perjuicios a los intereses públicos por las talas y cortes inmoderados que practican los compradores y a los intereses particulares de la excomunidad por el estorbo que esas ventas pondrán a la conclusión de las operaciones del reparto, pues si hubiera que modificar algo de las medidas adoptadas, se tropezaría con el inconveniente de la enajenación de los terrenos y montes.

El Gobernador del Estado ha tenido a bien acordar que esa Prefectura averigüe con escrupulosidad lo que haya de cierto en el particular y en caso afirmativo, dictará las providencias convenientes para que los indígenas no vendan los terrenos que inicialmente se les han señalado [...]”.

Morelia, marzo 11 de 1901. Firma: J. M. G. Real.

(AGHPEM, libro \#3, s/n foja). 


\section{RefleXiones FINALES}

El esfuerzo sostenido durante más de un siglo (todo el XIX y gran parte del xx) por mantenerse como estructuras organizativas viables frente a un sistema que las acosaba y que en diferentes momentos pretendió su franca disolución mostró facetas muy distintas y contrastantes. Según la información que aparece en los libros de hijuelas, ${ }^{13}$ aun cuando algunas comunidades aceptaron temporalmente y realizaron el reparto de tierras comunales, ideológicamente no se imaginaron exclusivamente como ciudadanos individuales y a la par siguieron reivindicando y utilizando las formas comunales de representación. A esto se le suma el hecho de que formalmente el proceso de privatización de la tierra quedó inconcluso, ya que hay muy poca evidencia de que se hayan elaborado y entregado los títulos de propiedad a cada parcelero (o porcionero). Por consiguiente, las tierras no se pudieron enajenar, comprar o vender de manera legal y si lo hicieron, fue (como se realiza hasta la fecha) mediante acuerdos internos, validados por la autoridad y respetados por toda la comunidad, pero que no lograron tener una objetivación en un documento legal reconocido por las autoridades nacionales (ie., por los representantes del Estado). Por lo que la posible incidencia en la conciencia de las personas, de llegar a considerarse exclusivamente ciudadanos en cuanto propietarios individuales y por consiguiente actuar en consecuencia en el espacio público, nunca se consolidó, quedando truncado este proceso con el advenimiento del movimiento armado de 1910.

De manera paradójica, la dinámica del reconocimiento de límites precisos y la búsqueda de "solución" a los conflictos y disputas entre comunidades (requisito fundamental para concluir el reparto de tierras en esta época) y sobre todo la "conversión" de la tierra en un bien económico susceptible de ser introducido al mercado capitalista condujo a la reafirmación del sentimiento de pertenencia a una corporación que poseía (o tenía en su haber) un territorio comunal

\footnotetext{
${ }^{13}$ Revisamos para este trabajo en el Archivo General e Histórico del Poder Ejecutivo de Michoacán los libros 3, 12 y 21 del Distrito de Uruapan, que contienen información sobre el reparto agrario en las comunidades de Sevina, Tanaco, Nahuatzen y su entorno.
} 
claramente delimitado con fronteras precisas del cual no podía cederse ninguna porción ni a sus vecinos ni a ningún particular ajeno a la comunidad, justamente porque además del valor simbólico se le agregó valor económico en su misma definición. En este sentido parece justa la sentencia de Roseberry de que si bien

formalmente las comunidades fueron abolidas, [pero] en la práctica y sustancialmente siguieron existiendo como entidades poseedoras de tierras durante el Porfiriato [y agregaríamos hasta la fecha]. Los repartos fueron parciales y desafiados, la mayoría de ellos no fueron finalizados hasta la primera década del siglo xx y algunos aún estuvieron en proceso cuando estalló la revolución (Roseberry 2004, 44-45).

A lo largo del siglo $\mathrm{xx}$, las comunidades indígenas echaron mano de diversas estrategias que van desde la invisibilización y conversión en comunidades campesinas, en muchos casos desde la primera mitad del siglo xx, hasta la recuperación de sus estructuras comunitarias y el reforzamiento de sus formas de gobierno y control social. Así pues, tenemos por un lado excomunidades - como se les llamó formalmente- que en algún momento y llevadas por su misma dinámica interna de divisiones y conflictos decidieron repartirse sus tierras y presentarse como comunidades agrarias o como simples comunidades de campesinos (proceso que bien ha descrito Boyer 2003) como sucedió en la zona otomí, mazahua, matlatzinca del oriente de Michoacán. Es decir, se "campesinizaron" y su identidad étnica se invisibilizó prácticamente durante todo el siglo xx. Por otro lado, aparecen las comunidades que durante todo el siglo XIX y principios del xx resistieron a través de diversos mecanismos y estrategias y que si bien transformaron sus formas de gobierno, ${ }^{14}$ sus sistemas de reciprocidad y redistribución de la riqueza y en cierto sentido también sus formas de representación siguen manteniendo un fuerte sentido de comunidad. No obstante, en la actualidad ambas reclaman se les reconozca como sujetos colectivos.

${ }^{14}$ Como lo ejemplifica el caso de Cherán, estudiado por Calderón 2004. 
¿Que significaba "nación” y que "comunidad” en la meseta purépecha en el siglo XIX? Curiosamente este siglo que fue un periodo de clara construcción de la nación mexicana, el proyecto nacional no significó siempre lo mismo, ni para sus propios "impulsores", como las elites criollas de los ciudadanos nacionalistas (citadinos), ni tampoco para los grupos campesinos. De la misma manera "comunidad" o la idea de vivir en comunidad tampoco significó lo mismo, ni para los intelectuales liberales ni para los mismos indígenas, como tampoco soberanía, ciudadanía, territorio, etcétera. Como lo deja claro Lampérière (2003), la nación mexicana primera pasó de ser concebida como una amalgama o república conformada por distintas corporaciones, con sus propios derechos reconocidos y oficialmente católica a una república de liberales conformada por individuos, secular y volcada a la búsqueda de las reformas que permitieran el desarrollo capitalista y la modernización social (donde la ciudadanía individual estuviera apoyada en la idea de igualdad de oportunidades para todos) y que de esta manera lograra sacar de su "atraso" a la gran masa campesina (que finalmente terminó levantándose en una revolución).

En el caso específico de Michoacán, luego de un siglo de disputas, negociaciones y resistencias - prácticamente todo el XIX y parte del xx- los miembros de las comunidades purépechas, llegarán a concebirse como ciudadanos pero con varias y diversas adscripciones, para ellos no necesariamente contradictorias, ni excluyentes. ${ }^{15}$

El hecho de que la relación entre identidad étnica, pertenencia a una comunidad y ciudadanía individual no sea necesariamente de exclusión, o que la adopción de una niegue la otra, nos muestra que para los actores el juego de las identidades, no es necesariamente de suma cero, sino que la identidad étnica y la ciudadanía individual son perfectamente compatibles en la vida cotidiana de estas personas. Aspecto que se manifiesta desde el siglo xIx y que con diferentes tesituras lo hará durante todo el siglo xx.

${ }^{15}$ Lo que cuestiona la teoría indigenista del siglo xx que concebía a las comunidades como unidades aisladas y enfrentadas y que definía (como lo hizo Caso) indígena como aquel que se siente pertenecer a una comunidad indígena, cuando en realidad también se sentían pertenecer a la nación. 


\section{REFERENCIAS}

AghPEM: Archivo General e Histórico del Poder Ejecutivo de Michoacán.

Annino, Antonio, "Pueblos, liberalismo y nación en México", en Antonio Annino y F.X. Guerra, coords., Inventando la nación. Iberoamérica en el siglo XIX, México, FCE, 2003.

BELLO, Álvaro, Espacios reconstruidos, territorios resignificados, Tesis de Doctorado, México, unAm-Facultad de Filosofía y Letras, 2007. Boyer, Christopher, Becoming Campesinos. Politics, identity, and agrarian struggle in posrevolutionary Michoacán, 1920-1935, Stanford, Stanford University Press, 2003.

Calderón, Marco Antonio, Historias, procesos politicos y cardenismos. Cherán y la sierra p’urhépecha, El Colegio de Michoacán, Zamora, 2006.

GledHILl, John, "Introducción. Pensando acerca del presente a través del pasado", en Andrew Roth, ed., Recursos contenciosos. Ruralidad y reformas liberales en México, Zamora, El Colegio de Michoacán, 2004.

LEMPÉRIÈRE, Annick, "De la república corporativa a la nación moderna”, en Annino y Guerra, coords., Inventando la nación. Iberoamérica en el siglo XIX, México, FCE, 2003.

LirA, Andrés, El Estado liberal y las corporaciones en México”, en Annino y Guerra, coords., Inventando la nación. Iberoamérica en el siglo XIX, México, FCE, 2003.

Mallon, Florencia, Peasant and Nation, Berkeley, Los Ángeles, Londres, University of California Press, 1995.

Muñoz, Óscar, Permanencia en el tiempo, Zamora, El Colegio de Michoacán, 2009.

Purnell, Jennie, “'Con todo el debido respeto'. La resistencia popular a la privatización de tierras comunales en el Michoacán del siglo XIX" en Andrew Roth, ed., Recursos contenciosos. Ruralidad y reformas liberales en México, Zamora, El Colegio de Michoacán, 2004.

Roseberry, William, “'El estricto apego a la ley'. Ley liberal y derecho comunal en el Pátzcuaro porfiriano”, en Andrew Roth, ed., 
Recursos contenciosos. Ruralidad y reformas liberales en México, Zamora, El Colegio de Michoacán, 2004.

ToCqueville, Alexis, La democracia en América, México, FCE, 1957. VILlEgas, Abelardo México en el horizonte liberal, México, UnAM, 1981.

Walzer, Michel, Las esferas de la justicia, México, FCE, 2001.

FECHA DE RECEPCIÓN DEL ARTículo: 15 de julio de 2010

FECHA DE ACEPTACIÓN Y RECEPCIÓN DE LA VERSIÓN FINAL: 5 de diciembre de 2010 